Marquette University

e-Publications@Marquette

College of Nursing Faculty Research and

Publications

Nursing, College of

6-2019

\title{
Qualitative Methods of Road Traffic Crash Research in Low- and Middle-income Countries: A Review
}

\author{
Benjamin D. Holmes \\ Medical College of Wisconsin \\ Kristin Haglund \\ Marquette University, kristin.haglund@marquette.edu \\ Kirsten M.M. Beyer \\ Medical College of Wisconsin \\ Laura D. Cassidy \\ Medical College of Wisconsin
}

Follow this and additional works at: https://epublications.marquette.edu/nursing_fac

Part of the Nursing Commons

\section{Recommended Citation}

Holmes, Benjamin D.; Haglund, Kristin; Beyer, Kirsten M.M.; and Cassidy, Laura D., "Qualitative Methods of Road Traffic Crash Research in Low- and Middle-income Countries: A Review" (2019). College of Nursing Faculty Research and Publications. 790.

https://epublications.marquette.edu/nursing_fac/790 
Marquette University

e-Publications@Marquette

\section{Nursing Faculty Research and Publications/College of Nursing}

This paper is NOT THE PUBLISHED VERSION; but the author's final, peer-reviewed manuscript. The published version may be accessed by following the link in the citation below.

International Journal of Injury Control \& Safety Promotion, Vol. 26, No. 2 (June 2019): 194-199. DOI. This article is (C) Taylor \& Francis Group and permission has been granted for this version to appear in e-Publications@Marquette. Taylor \& Francis Group does not grant permission for this article to be further copied/distributed or hosted elsewhere without express permission from the Taylor \& Francis Group.

\section{Qualitative Methods of Road Traffic Crash Research in Low- And Middle-Income Countries: A Review}

Benjamin D. Holmes

Institute for Health \& Equity, Medical College of Wisconsin, Milwaukee, WI

Kristin Haglund

College of Nursing, Marquette University, Milwaukee, WI

Kristin M. M. Beyer

Institute for Health \& Equity, Medical College of Wisconsin, Milwaukee, WI

Laura D. Cassidy

Institute for Health \& Equity, Medical College of Wisconsin, Milwaukee, WI

\section{Introduction}

Road traffic crashes are rapidly becoming one of the leading causes of injury and death globally. It is predicted that by 2030 crashes will become the fourth leading cause of disability-adjusted life years 
(DALYs) (Mathers \& Loncar, [11]) and the seventh leading global cause of death (World Health Organization [WHO], [26]). The global death toll due to crashes has already escalated by $46 \%$ over the past two decades (The World Bank, [21]).

Low- and middle-income countries (LMICs) are acutely affected by this 'hidden epidemic' (Balch, [ 1]). Ninety per cent of the world's crash-related deaths occur in LMICs where only $54 \%$ of its motor vehicles are registered (WHO, [25]). Furthermore, the economic toll of crashes in LMICs is concerning because nearly one half of all health care expenditures in LMICs is used to treat injuries related to motor vehicle crashes (Zakeri \& Nosratnejad, [28]). This epidemic deserves urgent attention (Lin, [10]).

Research on the epidemiology of crash problems in LMICs is increasing but these research efforts predominantly report statistics. There is a paucity of qualitative research that could help to explain the statistics. Qualitative exploration has the potential to enhance crash research by describing and explicating the contexts and social processes surrounding crashes, such as the antecedents, the environments in which crashes occur and injuries are produced, and the behaviours of people which make crashes more likely (Roberts, [14]; Rothe, [16]). Qualitative research methods can spark and mobilize the ideas and efforts of affected community members, thereby optimizing crash prevention interventions. Additionally, incorporating local citizens' perspectives on the nature, causes and potential solutions of traffic problems in their locale increases the likelihood that proposed solutions will be effective, wanted and beneficial (Roberts, Smith, \& Bryce, [15]).

This article will review the literature to assess the extent to which qualitative methods have been implemented to research road traffic crashes in LMICs and to inform future methodological decisionmaking.

\section{Materials and methods}

\section{Eligibility criteria}

Papers were considered eligible for inclusion if they were related to attitudes towards, or the experience of, road traffic crashes in LMICs, as portrayed by any of the following stakeholders: crash survivors, crash victims' social networks, motor vehicle drivers, first responders, law enforcement, medical providers, community members, and policymakers. Only papers published after 2000 and with abstracts written in or translated into English were included. To reduce redundancy, literature reviews and meta-analyses were excluded.

\section{Information sources and search criteria}

The following electronic databases were queried: MEDLINE, EMBASE, Scopus, Transport Research International Documentation (TRID) and Google Scholar. Google Scholar results were further researched by analysing papers which cited them.

The following phrases were used in querying the above databases for appropriate titles and abstracts: 'qualitative road traffic', 'qualitative crash traffic', 'qualitative accident traffic' and 'qualitative injury traffic'. These phrases were then appended by 'LMIC' and searches were repeated. 


\section{Study selection}

In all, 39 studies met the inclusion criteria. Full texts of these studies were then reviewed and analysed. Two studies were excluded, one of which was a systematic review and meta-summary of the effectiveness of crash prevention initiatives in LMICs (Staton et al., [19]), and the claims of another of which that the study was a qualitative analysis were unsubstantiated (Debata, Deswal, \& Kumath, [ 3]).

\section{Results}

A summary of qualitative research and analytical methods and WHO regions where the studies were performed are presented in Table 1 (WHO, [24]). The included studies were published between 2003 and 2017. A frequency analysis of studies by publication year is presented in Figure 1 . Of the 37 studies, 35 reported performing interviews, 24 (69\%) of which were semi-structured, and 11 (32\%) were structured. In total, 11 studies involved focus groups, and one of these studies also utilized a nominal group, which is a follow-up discussion group made up of participants selected from previously held focus groups. Finally, four of the studies reported observational research methods. Several studies performed a combination of the above research methods, summarized in Table 2 . The selected studies employed a variety of analytical methods, including content analysis (seven studies), grounded theory (six), thematic analysis (four), phenomenology (three), and ethnography (two). A few of the studies did not report their analytical methods.

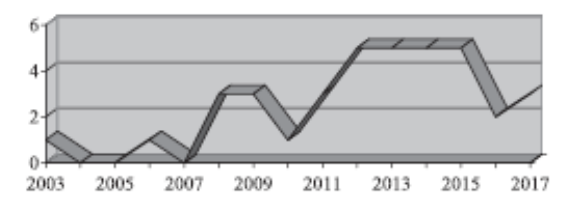

Figure 1. Frequency analysis of studies by publication year. 
Table 1. Qualitative research and analytical methods by WHO region.

\begin{tabular}{|c|c|c|c|c|c|c|}
\hline Methods & Studies, $\mathrm{n}=37 \mathrm{n}(\%)$ & $\begin{array}{l}\text { Eastern } \\
\text { Mediterranean, } n=11 \\
(30 \%)\end{array}$ & $\begin{array}{l}\text { Americas, } n=10 \\
(27 \%)\end{array}$ & $\begin{array}{l}\text { Africa, } n=7 \\
(19 \%)\end{array}$ & $\begin{array}{l}\text { South-East } \\
\text { Asia, } n=6 \\
(16 \%)\end{array}$ & $\begin{array}{l}\text { Western } \\
\text { Pacific, } n=3 \\
(8 \%)\end{array}$ \\
\hline \multicolumn{7}{|l|}{ Research } \\
\hline Interview & $35(95 \%)$ & & & & & \\
\hline Semi-structured & $24(65 \%)$ & 9 & 7 & 5 & 3 & \\
\hline Structured & $11(30 \%)$ & 2 & 1 & 2 & 4 & 2 \\
\hline Focus groups & $11(30 \%)$ & 2 & 4 & 2 & 3 & \\
\hline Nominal groups & $1(3 \%)$ & & 1 & & & \\
\hline Observation & $4(11 \%)$ & 1 & 1 & 1 & & 2 \\
\hline \multicolumn{7}{|l|}{ Analysis } \\
\hline Content analysis & $7(19 \%)$ & 2 & 1 & 2 & 2 & \\
\hline Grounded theory & $6(16 \%)$ & 5 & 1 & & & \\
\hline Thematic analysis & $4(11 \%)$ & 1 & 1 & 1 & 1 & \\
\hline Phenomenology & $3(8 \%)$ & 1 & 1 & & 1 & \\
\hline Ethnography & $2(5 \%)$ & 1 & 1 & & & \\
\hline
\end{tabular}

Table 2. Combinations of qualitative research methods.

\begin{tabular}{|l|l|l|l|l|l|}
\hline & Semi-structured interviews & Structured interviews & Focus groups & Nominal groups & Observations \\
\hline Semi-structured interviews & & 1 & 6 & 0 & 2 \\
\hline Structured interviews & 1 & & 3 & 0 & 1 \\
\hline Focus groups & 6 & 3 & & 1 & 0 \\
\hline Nominal groups & 0 & 0 & 1 & & \\
\hline Observations & 2 & 1 & 0 & 0 & \\
\hline
\end{tabular}

The texts of each of the included papers were studied, resulting in the emergence of six crash-related themes: ( 1 ) the causes of crashes and the crash epidemic, ( 2) driver behaviourisms, (3) the experience of the crash, (4) the experience of injury care including pre-hospital care, (5) crash prevention and intervention, and (6) motivations for risky driving. Themes were predominantly studied using established research 
and analytical methods (Tables 3 and 4). For instance, all of the included studies addressing driver behaviourisms used observational research methods, and half of the studies addressing crash intervention and prevention analysed data using grounded theory.

Table 3. Themes by research methods.

\begin{tabular}{|c|c|c|c|c|c|c|}
\hline & Themes & & & & & \\
\hline Research methods & $\begin{array}{l}\text { Crash aetiology } n \text { (\% of } \\
\text { method, \% of theme) }\end{array}$ & $\begin{array}{l}\text { Driver } \\
\text { behaviourisms }\end{array}$ & $\begin{array}{l}\text { Experience of } \\
\text { crash }\end{array}$ & Injury care & $\begin{array}{l}\text { Prevention \& } \\
\text { intervention }\end{array}$ & $\begin{array}{l}\text { Risky driving } \\
\text { motivations }\end{array}$ \\
\hline Semi-structured interviews & $5(16,36 \%)$ & 0 & $7(22,78 \%)$ & $6(19,50 \%)$ & $8(25,62 \%)$ & $6(19,60 \%)$ \\
\hline Structured interviews & $5(45,36 \%)$ & 0 & $1(9,11 \%)$ & $2(18,17 \%)$ & $2(18,15 \%)$ & $1(9,10 \%)$ \\
\hline Focus groups/nominal groups & $4(31,29 \%)$ & 0 & 0 & $3(23,25 \%)$ & $3(23,23 \%)$ & $3(23,30 \%)$ \\
\hline Observation & 0 & $3(60,100 \%)$ & $1(20,11 \%)$ & $1(20,8 \%)$ & 0 & 0 \\
\hline $\begin{array}{l}\text { Interview/focus group } \\
\text { combination }\end{array}$ & $3(33,21 \%)$ & 0 & 0 & $2(22,17 \%)$ & $1(11,8 \%)$ & $3(33,30 \%)$ \\
\hline $\begin{array}{l}\text { Interview/observation } \\
\text { combination }\end{array}$ & 0 & 0 & $1(50,11 \%)$ & $1(50,8 \%)$ & 0 & 0 \\
\hline
\end{tabular}

Table 4. Themes by analytical methods.

\begin{tabular}{|l|l|l|l|l|l|l|}
\hline & Themes & & & & \\
\hline $\begin{array}{l}\text { Analytical } \\
\text { methods }\end{array}$ & $\begin{array}{l}\text { Crash aetiology } \mathrm{n} \text { (\% of } \\
\text { theme) }\end{array}$ & $\begin{array}{l}\text { Driver } \\
\text { behaviourisms }\end{array}$ & $\begin{array}{l}\text { Experience of } \\
\text { crash }\end{array}$ & $\begin{array}{l}\text { Injury } \\
\text { care }\end{array}$ & $\begin{array}{l}\text { Prevention \& } \\
\text { intervention }\end{array}$ & $\begin{array}{l}\text { Risky driving } \\
\text { motivations }\end{array}$ \\
\hline Content analysis & $2(50 \%)$ & 0 & $2(50 \%)$ & $1(33 \%)$ & $1(13 \%)$ & $1(20 \%)$ \\
\hline Grounded theory & 0 & 0 & 0 & $2(67 \%)$ & $4(50 \%)$ & $1(20 \%)$ \\
\hline Thematic analysis & $2(50 \%)$ & 0 & 0 & 0 & $2(25 \%)$ & $2(40 \%)$ \\
\hline Phenomenology & 0 & 0 & $2(50 \%)$ & 0 & $1(13 \%)$ & 0 \\
\hline Ethnography & 0 & 0 & 1 & 0 & 0 & $1(20 \%)$ \\
\hline
\end{tabular}


Senior authors were from the respective LMIC countries in 28 studies.

\section{Qualitative research methods}

\section{In-depth interviews}

\section{Semi-structured}

In all, 24 studies used semi-structured interviews. Interviewee identities spanned the breadth of road traffic crash stakeholders, including crash survivors (motorcycle, car, bus, and truck drivers; passengers; and pedestrians), victims' families, law enforcement, medical caregivers, and policymakers. These semi-structured interview papers addressed five of the above six themes: prevention and intervention (eight papers), the crash experience (seven), the experience of injury care (six), motivations of risky driving (six), and crash aetiology (five). Raynor and Mirzoev ([13]), for example, utilized semi-structured interviews to address factors in crash aetiology in Kenya, arguing that while existing research adequately describes the main causes of crashes in Kenya, interviews were necessary to understand why the crashes are occurring. After performing semi-structured interviews with minibus drivers, the authors determined several barriers to road traffic safety in Kenya. The barriers identified financial pressures on minibus drivers which influence safe driving decisions and police corruption. These unique perspectives were obtained solely through the use of semi-structured interviews.

\section{Structured}

In all, 11 studies used structured interviews. Interviewees were sampled from crash survivors (motorcycle, car, and truck drivers, and passengers), law enforcement, and medical caregivers. Five themes regarding road traffic crashes emerged: (1) crash aetiology (five papers), (2) prevention and intervention (two), ( 3 ) the experience of injury care (two), (4) the crash experience (one), and (5) motivations of risky driving (one). Like semi-structured interviews, structured interviews are utilized to understand the causes and processes of phenomena (Talukder, Islam, Ahmed, \& Raihan, [20]). A benefit of structured over semi-structured interviews is that the data are collected in such a way to lend themselves more readily to data analysis. However, structured interviews can fail to gather the same richness of data that semi-structured interviews can capture. Thus, structured interviews are frequently combined with other research methods to obtain the highest quality of information. For example, in this review, only $38 \%(9 / 24)$ of semi-structured interview papers coupled interviews with other methods, whereas $46 \%$ (5/11) of structured interview papers combined methods.

\section{Focus groups}

In all, 11 studies involved focus groups. Focus group participants included the following: community members, crash survivors (motorcycle, car, and truck drivers; passengers; and pedestrians), law enforcement, medical caregivers, school teachers, and policymakers. Focus group papers addressed four themes regarding road traffic crashes: ( 1) crash aetiology (four papers), (2) motivations for risky driving (three), (3) the experience of injury care (three), and (4) prevention and intervention (two). Trevino-Siller, Hijar, and Mora ([22]) also utilized nominal groups as a follow-up to focus groups. Their study's two nominal groups consisted of participants who were selected from previously held focus groups, which discussed crash causes, consequences, and priority interventions in Cuernavaca, Mexico. The nominal groups then convened and discussed relevant crash interventions more extensively. These 
researchers utilized nominal groups to streamline a list derived from focus groups consensus of priority crash interventions.

\section{Observation}

Four studies utilized an observational method. Observational methods were used almost exclusively to understand motor vehicle driver behaviourisms (three of the four studies), and $100 \%(3 / 3)$ of the studies addressing driver behaviourisms utilized observational methods.

\section{Combinations}

In all, 14 studies combined two of the above research methods to study crash factors in greater depth. Studies included in this review combined methods to address factors such as crash aetiology (three papers), motivations for risky driving (three), the experience of injury care (three), prevention and intervention (one), and the crash experience (one). Zamani-Alavijeh et al. ([29]) augmented data from focus group sessions exploring motorcycle crash-related risk factors in Iran with data from in-depth interviews, finding that motorcyclists' risky behaviours were related to certain motivational factors, such as convenience, occupation, thrill seeking, and criminal activity. The authors posited that adding interviews to focus groups allowed them to collect additional data in a confidential setting that would not have been discussed in a focus group setting.

\section{Qualitative analytical methods}

\section{Content analysis}

Content analysis was the most commonly described analytical technique and was used in seven studies. Content analysis describes the meaning of textual data and systematically reduces the data into categories or meaning units (Schreier, [18], 170-183). The frequency of these text categories is measured and the data are categorized (Vaismoradi, Turunen, \& Bondas, [23]). Sanusi and Emmelin ([17]) analysed semi-structured interview data from commercial motorcycle drivers in Ibadan, Nigeria to understand motivations behind risky driving decisions. The authors suggested that this particular analytical approach generated data of both the manifest meaning and underlying latent meaning of interview texts. After performing interviews, the authors obtained meaning units from texts, condensed the meaning units and used them to generate codes, and then grouped the codes together to form categories to describe the texts' manifest meaning. Latent meanings were then deduced through forming themes based on further developing the categories. The authors found that risky driving was motivated by social norms, occupation requirements and earning efficiency.

\section{Grounded theory}

Grounded theory is a specific type of content analysis. It also categorizes textual data, but then proceeds further to generate theory which is 'grounded' in the data (Forman \& Damschroder, [ 4], 3962). Thus, grounded theory is a preferred method when the researcher's objective is to develop a theory that can explain human behaviour in context (Munhall, [12], 230). Haghparast-Bidgoli, Khankeh, Johansson, Yarmohammadian, and Hasselberg ([5]) utilized grounded theory to develop a theory or framework explaining trauma care delivery for road traffic crash patients in emergency departments in Iran. The authors analysed semi-structured interview data from health professionals and patients in three ways. First, the authors scrutinized interview texts line by line to discover codes. They then 
labelled and grouped similar codes into categories and subcategories. Next, the authors specified relationships between categories to further conceptualize them. Finally, the authors identified one core category which related to each of the other categories, namely the lack of a systematic approach in trauma care provision.

Grounded theory used in six studies generated the following frameworks: educational campaigns focused on structural interventions to improve knowledge of and attitudes towards crashes (Khorasani-Zavareh et al., [ 8], [ 9]); interventions targeting motorcycle safety to provide tailored incentives by type of motorcyclist - risk managers, risk utilizers, risk calculators, and risk takers (Bazargan-Hejazi, Zamani-Alavijeh, Hindman, Mohamadi, \& Bazargan, [ 2]); and a systems approach to address crash policy to engage multi-sectoral stakeholders (Huicho et al., [ 6]).

\section{Thematic analysis}

Thematic analysis was utilized by authors in four studies to analyse textual data. Thematic analysis is similar to content analysis but differs from it in its analytical process, whereas content analysis quantifies data by reducing them into categories based on concrete passages in the text, thematic analysis emphasizes the context of the data, aiming to integrate rather than divide manifest and latent textual contents (Vaismoradi et al., [23]). Zamani-Alavijeh et al. ([29]) thematically analysed data from focus groups and interviews with motorcyclists, passengers, and police to determine factors of both crash-related risk behaviours and motivations. The authors simultaneously collected and analysed data, allowing new data to determine the integrity of the developing analysis. Data were categorized and compared within and across categories as well as across interviews, and categories were thus developed and refined iteratively. Themes thereby emerged and developed until saturation was achieved and new interviews no longer yielded new themes. Manifest and latent themes were thus integrated throughout the analysis, resulting in seven risk behaviours and four related motivational factors.

\section{Phenomenology}

A phenomenological approach was used in three studies. The preeminent focus in phenomenological crash research is understanding the meaning of the crash-related experience. Phenomenological inquiry is undergirded by the researcher's 'decentred' accounting for self- and others' beliefs, and initiated by researcher/participant interaction, such as in interviews. Textual analysis is then performed, not just of verbal interaction, but of the shared situated context of researcher and participant; the factors which potentially motivate action or inaction; the spatial, embodied, temporal, and relational world inhabited by the participant; and more globally, the historical, political, cultural, and social framework which structures the researcher/participant interaction (Munhall, [12], 163). Each of these factors is explored and accounted for throughout the analysis. Finally, keywords and phrases from the texts are identified and coded to create categories and nodes, which are ultimately categorized into themes.

In one study, researchers performed a phenomenological analysis of semi-structured interviews with crash survivors of maxillofacial trauma in Nepal, in an effort to understand survivors' experiences of both the crash and his/her care (Yadav \& Shrestha, [27]). The authors initiated the analysis with a repeated, in-depth reading of interview transcripts to discern researcher/participant contexts. This was 
followed by line by line textual analysis, the categorization of keywords and phrases, and the development of nodes and themes. The authors concluded that this phenomenological analysis led to discernment of data which could not otherwise 'be obtained by the use of surveys and test questions'.

\section{Ethnography}

Authors of two studies analysed data using ethnographic methods. An ethnography is a study taking a naturalistic, immersive, systematic, interpretive approach to data collection and analysis (Munhall, [12], 295). Ethnographic data are an understanding between researcher and participant of the 'insiders' worlds' through observation, interview and analysis (of events, documents and artefacts) (Munhall, [12], 285). By analysing these data, the researcher seeks to derive a theoretical framework with findings such as hypotheses about behaviour, interpretation theories (with associated definitions and typologies) and constructs (Munhall, [12], 318). One crash ethnography included in this review studied the role fatalistic beliefs play in risky decision-making by drivers in Pakistan (Kayani, King, \& Fleiter, [ 7]). The authors engaged in semi-structured interviews with drivers, religious leaders, policymakers and law enforcement regarding the possible causes of crashes, personal experiences with crashes, driving behaviours, prevention and intervention tactics, and beliefs surrounding fatalism. Data were then analysed whereby the authors developed a construct of fatalism's role in risky driving, concluding that fatalistic beliefs are pervasive in Pakistan and that they can obstruct road safety public messages and promote risky road use.

\section{Discussion}

The aim of this article was to review the literature to assess the extent to which qualitative methods have been implemented to research road traffic crashes in LMICs and to inform future methodological decision-making. While implementation of these methods has historically been limited, numbers of qualitative crash research publications are generally rising, mimicking the upswing of this epidemic (Figure 1). This trend could indicate a greater awareness in the scientific community of the value of qualitative methods in crash research and emphasizes the value of this article's results in guiding future efforts.

The use of a variety of qualitative research and analytical methods was demonstrated in the studies with the majority of studies utilizing interviews to obtain data and content analysis as an analytical method. In all, 14 studies combined research methods, nine of which combined interviews with focus groups. Consideration of the studies' objectives, themes, and research and analytical methods identifies potential methods for conducting crash research in LMICs (Tables 3 and 4). Using structured interviews coupled with focus groups is a popular approach because the focus groups can expand and enrich the data provided by structured interviews. Of the 14 papers addressing crash aetiology, five have utilized structured interviews though there is also precedence for using semi-structured interviews, focus groups and semi-structured interviews combined with focus groups. Content and thematic analyses were equally cited as analytical methods addressing crash aetiology. All papers assessing driver behaviourisms used an observational methodology. Additionally, the experience of crashes was predominantly studied via semi-structured interviews and analysed equally with phenomenology and content analysis. Injury care was studied fairly equally by each method but was predominantly analysed via grounded theory. Prevention and intervention were also fairly equally studied using semi-structured interviews, structured interviews and focus groups; grounded theory 
and thematic analysis were utilized by $75 \%$ of papers addressing prevention and intervention. Risky driving motivations were primarily studied via focus groups and semi-structured interviews. Most risky driving motivation data were analysed via thematic analysis though ethnography, content analysis and grounded theory were also used. The themes most commonly studied via combining research methods were crash aetiology and risky driving motivation; both these themes were analysed via combining interviews and focus groups.

\section{Conclusion}

The studies using qualitative methods focused on road traffic crash data in LMICs are sparse. However, given this review's inclusion criterion of abstracts written in or translated into English, it is possible that other non-English qualitative studies exist. The qualitative methods employed in the included studies have been implemented successfully. Researchers interested in studying crash aetiology, driver behaviourisms, crash experiences, injury care, crash prevention and intervention, and risky driving motivations should consider the research and analytical methods presented in this review as appropriate options.

\section{Disclosure statement}

No potential conflict of interest was reported by the authors.

\section{References}

1 Balch, O. (2013). Road deaths, cancer and diabetes becoming Africa's hidden epidemics. The Guardian, Retrieved from https://www.theguardian.com/globaldevelopment/2013/aug/05/road-deaths-cancer-diabetes-africa.

2 Bazargan-Hejazi, S., Zamani-Alavijeh, F., Hindman, D., Mohamadi, E., \& Bazargan, M. (2013). How do motorcyclists manage mental tensions of risky riding? BMC Public Health, 13, 865.

3 Debata, P. K., Deswal, S., \& Kumath, M. (2014). Causes of unnatural deaths among children and adolescents in northern India - a qualitative analysis of postmortem data. Journal of Forensic and Legal Medicine, 26, $53-55$.

4 Forman, J., \& Damschroder, L. (2007). Qualitative content analysis. In Empirical methods for bioethics: A primer (pp. 39 -62). Bingley, UK : Emerald Group Publishing Limited.

5 Haghparast-Bidgoli, H., Khankeh, H., Johansson, E., Yarmohammadian, M. H., \& Hasselberg, M. (2013). Exploring the provision of hospital trauma care for road traffic injury victims in Iran: $A$ qualitative approach. Journal of Injury and Violence Research, 5 (1), 28 - 37.

6 Huicho, L., Adam, T., Rosales, E., Paca-Palao, A., Lopez, L., Luna, D. ... PIAT Working Group. (2012). Evaluation of interventions on road traffic injuries in Peru: A qualitative approach. BMC Public Health, 12, 71.

7 Kayani, A., King, M. J., \& Fleiter, J. J. (2012). Fatalism and its implications for risky road use and receptiveness to safety messages: A qualitative investigation in Pakistan. Health Education Research, 27, $1043-1054$.

8 Khorasani-Zavareh, D., Khankeh, H. R., Mohammadi, R., Laflamme, L., Bikmoradi, A., \& Haglund, B. J. (2009a). Post-crash management of road traffic injury victims in Iran: Stakeholders' views on current barriers and potential facilitators. BMC Emergency Medicine, 9, 8. 
9 Khorasani-Zavareh, D., Mohammadi, R., Reza Khankeh, H., Laflamme, L., Bikmoradi, A., \& Haglund, B. J. (2009b). The requirements and challenges in preventing of road traffic injury in Iran. $A$ qualitative study. BMC Public Health, 9, 486.

Lin, Y. (2016). The global distribution of the burden of road traffic injuries: Evolution and intradistribution mobility. Journal of Transport Geography, 56, 77 - 91.

Mathers, C. D., \& Loncar, D. (2006). Projections of global mortality and burden of disease from 2002 to 2030. PLoS Medicine, 3, e442.

Munhall, P. L. (2012). Nursing research. Burlington, MA : Jones \& Bartlett Learning.

Raynor, N. J., \& Mirzoev, T. (2014). Understanding road safety in Kenya: Views of matatu drivers. International Health, 6, $242-248$.

Roberts, $H$. (1997). Qualitative research methods in interventions in injury. Archives of Disease in Childhood, 76, $487-489$.

Roberts, H., Smith, S. J., \& Bryce, C. (1995). Safety as a social value. Buckingham : Open University Books.

Rothe, J. P. (2000). Undertaking qualitative research: Concepts and cases in injury, health and social life. Edmonton, Canada : University of Alberta.

Sanusi, A. A., \& Emmelin, M. (2015). Commercial motorcycle drivers' perceptions of risk and road safety in urban Nigeria: An explorative study. International Journal of Injury Control and Safety Promotion, 22, 328 - 339.

Schreier, M. (2014). Qualitative content analysis (1st ed). In The SAGE handbook of qualitative data analysis (pp. $170-183$ ).

Staton, C., Vissoci, J., Gong, E., Toomey, N., Wafula, R., Abdelgadir, J., ... Hocker, M. (2016). Road traffic injury prevention initiatives: A systematic review and metasummary of effectiveness in low and middle income countries. Plos One, 11 (1), e0144971.

Talukder, M. M., Islam, S., Ahmed, I., \& Raihan, A. (2013). Causes of truck and cargo drivers' fatigue in Bangladesh. Jurnal Teknologi (Sciences and Engineering, 65, $75-80$.

The World Bank (2014). Transport for health: The global burden of disease from motorized road transport. Global Road Safety Facility. Institute for Health Metrics and Evaluation. Washington, DC: The World Bank; Seattle, WA: IHME.

Trevino-Siller, S., Hijar, M., \& Mora, G. (2011). Prioritisation of road traffic injury interventions: Results of a participative research with stakeholders in Mexico. International Journal of Injury Control and Safety Promotion, 18, $219-225$.

Vaismoradi, M., Turunen, H., \& Bondas, T. (2013). Content analysis and thematic analysis: Implications for conducting a qualitative descriptive study. Nursing \& Health Sciences, 15, $398-405$.

WHO regional offices. (2017). World Health Organization. Retrieved 10 May 2017, from http://www.who.int/about/regions/en/

World Health Organization (2015). 10 facts on global road safety. World Health Organization. Retrieved 18 April 2017, from http://www.who.int/features/factfiles/roadsafety/facts/en/.

World Health Organization (2016). Road traffic injuries - Fact sheet. World Health Organization. Retrieved 15 March 2017, from http://www.who.int/mediacentre/factsheets/fs358/en/.

Yadav, S. K., \& Shrestha, S. (2017). A study on posttraumatic experience of road traffic accident afflicted maxillofacial trauma patient at tertiary hospital. Journal of Natural Science, Biology and Medicine, 8 (1), 40.

Zakeri, R., \& Nosratnejad, S. (2017). 172: Economic burden of road traffic injuries in low and middle income countries versus high income countries: A systematic review. BMJ Open, 7 (Suppl 1), A63. 
Zamani-Alavijeh, F., Niknami, S., Bazargan, M., Mohammadi, E., Montazeri, A., Ahmadi, F., \& Ghofranipour, F. (2009). Accident-related risk behaviors associated with motivations for motorcycle use in Iran: A country with very high traffic deaths. Traffic Injury Prevention, 10, 237 $-242$. 